\title{
Mechanical Behavior of Tubular Freeze-Cast Substrates with Organized Pore Structure
}

\author{
Bruno Maciel Sousa ${ }^{a}$, Daniel Dornellas Athayde ${ }^{a^{*}}$ (1), Wander Luiz Vasconcelos ${ }^{a}$ \\ ${ }^{a}$ Universidade Federal de Minas Gerais (UFMG), Departamento de Engenharia Metalúrgica e de Materiais, \\ Escola de Engenharia, Avenida Presidente Antônio Carlos, 31270-901, Belo Horizonte, MG, Brasil.
}

Received: March 13, 2021; Revised: June 03, 2021; Accepted: July 08, 2021

\begin{abstract}
Despite the high potential of the freeze-casting technique for production of porous inorganic substrates, there is a lack of studies on tubular geometries and their mechanical behavior under different pressure scenarios. In this work, the mechanical behavior of tubular freeze-cast alumina substrates was assessed by mathematical models from experimental O-ring tests. The stress distributions revealed a concentration of tensile stresses (within $0.2-25.0 \mathrm{MPa}$ ) on the plane of the load, causing brittle fracture. Furthermore, the results confirmed that the honeycomb model for brittle material adequately predicted the mechanical strength of the tubular freeze-cast substrates. Finally, fracture criteria from honeycomb model was used to estimate the maximum homogeneously distributed pressures, such as in fluids, that the substrates can withstand. This configuration represents more precisely practical conditions, though is hard to experimentaly replicate. Therefore, the developed procedure is paramount to simulate the mechanical behaviour of the tubular freeze-cast substrates under real operating conditions.
\end{abstract}

Keywords: Freeze-Casting, Mechanical Properties, Tubular Substrates, Honeycomb Model, Failure Analysis, Modeling and Simulation, Alumina.

\section{Introduction}

Porous ceramic materials have been widely studied in the last years due to its high potential in applications such as: filters ${ }^{1-3}$, catalysis ${ }^{4,5}$, membranes $^{6-8}$ and bioceramics ${ }^{9,10}$. The high mechanical resistance, low thermal conductivity and considerable chemistry stability of ceramic materials make them ideal for harsher conditions frequently used on industrial applications $\mathrm{s}^{11,12}$. For the production of porous materials, the freeze-casting is a promising technique due to the aligned and interconnected pore structure, as shown in Figure $1 \mathrm{a}, \mathrm{b}$. The result is a material with porosities up to $99 \%^{13,14}$, typically with high values of open porosity. These characteristics of the freeze-cast substrates make them an interesting alternative for applications requiring anisotropic pore structure, such as those demanding materials with high fluid fluxes through the pores ${ }^{15,16}$. Nevertheless, these materials must have a proper mechanical resistance to withstand the typical pressures applied in industrial processes, making their use viable. Therefore, it is important to analyze the spatial distribution and intensities of stresses that cause material failure in highly porous ceramic substrates in order to design them with adequate mechanical stability.

The use of tubular substrates for separation applications usually involves pressure-driven processes, in which the substrates are immersed in a fluid and a pressure difference between the external and internal surfaces is applied. For instance, ceramic substrates used for membrane manufacture must be stable enough to endure pressures up to $10 \mathrm{MPa}^{17}$. Therefore, assessment of the mechanical behavior of ceramic

"e-mail: ddathayde@gmail.com substrates is critical for safe and widespread commercial use. The strength of ceramic tubes can be measured by many techniques, such as the compression test. Among those available, the O-ring diametral compression test is a convenient and simple test from the point of view of machinery and the sample load ${ }^{18}$. A simple analytical equation to estimate maximum tensile stress during O-ring compression tests was developed by Martinez et al. ${ }^{18}$. Despite its simplicity, this equation has limited application as it only takes into account ring dimensions and load of fracture. In addition, it does not allow estimation of the spatial stress distribution, which is required for thorough assessment of the fracture phenomenon.

Calculation of the spatial stress distribution during the O-ring test is not trivial. A mathematical model developed by Jadaan et al. ${ }^{19}$, and later improved by Kranendonk et al. ${ }^{20}$, allows estimation of the tensile and compressive stresses according to the position on the tubular material when the O-ring is submitted to diametral compression forces. A second mathematical development was performed by Gabriel Lamé ${ }^{21}$ by considering a system in which thick tubes are submitted to pressures homogeneously distributed on the surfaces. This model is widely used on the project of tubes and pressure vessels $^{22,23}$, since it represents more precisely the condition when tubular substrates are immersed in a fluid and submitted to a pressure difference (internally or externally) as a driving force for separation applications. Nevertheless, experiments implementing pressures homogeneously distributed in a tubular substrate are hard to be performed and, thus, an analytical failure criterion is frequently required to use Lamé's model. 

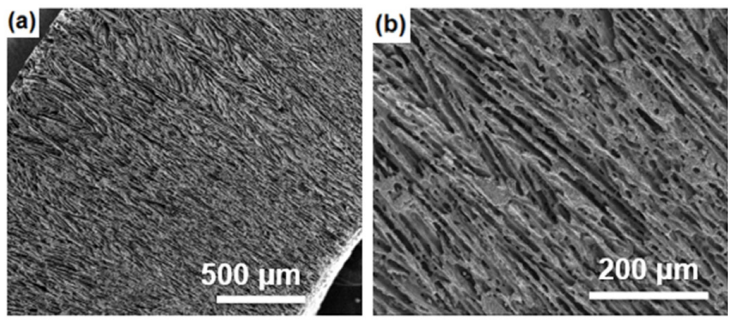

(c)

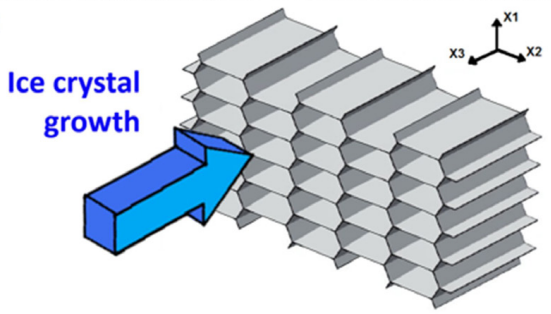

Figure 1. ( $a$ and $b$ ) Representative SEM micrographs showing the radially aligned macroporosity in freeze-cast substrates produced from alumina suspensions with $15 \%$ solid loading and sintered at $1400{ }^{\circ} \mathrm{C}$. (Reproduced from ${ }^{17}$ under Creative Commons Licence). (c) Schematic representation of a honeycomb structure. The pore geometry can be compared to the lamellar and elongated pores obtained in freeze-cast materials from water-based suspensions.

Regarding failure analysis of brittle materials, it has been shown that the honeycomb model is the most adequate to describe the mechanical behavior of porous freeze-cast materials ${ }^{13}$. This is due to the pore directionality, with constant transversal section, which is attributed to use of water as a solvent and a pore-forming agent $t^{13,24}$. Considering this pore geometry (Figure 1c), the failure criterion was further developed by Gibson et al. ${ }^{25}$. This model provides the maximum stresses supported by a honeycomb structure constituted of a fragile material (alumina), where both tensile and compressive scenarios can be analyzed by these equations using the appropriate modulus of rupture ${ }^{25}$. In addition, it provides a method to assess the variation of mechanical strength according to the load direction $\left(\mathrm{X}_{1}\right.$ or $\mathrm{X}_{2}$ as shown in Figure 1c). The honeycomb model has not been used, to the best of the author's knowledge, to assess the mechanical behavior of tubular freeze-cast substrates. This is a distinct geometry from traditional blocks and cylinders, and requires further analysis of the honeycomb model.

In previous work ${ }^{26}$, the freeze-cast substrates with radially aligned porosity were submitted to O-ring compression tests and the crushing strengths of such tubular substrates were analyzed by the Martinez's model ${ }^{18}$. The maximum tensile stresses were analyzed varying processing parameters (solid loading of the initial ceramic suspension and the sintering temperatures) in order to achieve the substrate with most adequate mechanical stability. The higher crushing strengths were obtained for higher values of both the solid loading and the sintering temperature, due to the effect that the processing parameters showed on structural properties (pore and grain sizes $)^{26}$.

In this work, mathematical models were used to further assess the stress distribution during the O-ring diametral compression tests, in order to estimate more accurately the fracture phenomenon. The spatial distribution allowed an analysis of the regions where tensile stresses are prevalent, as well as regions with compressive stresses. The tensile stresses found were slightly higher than the ones obtained by Athayde et al. ${ }^{26}$. In addition, the honeycomb model was applied to the freeze-cast alumina and proven adequate in predicting the tensile stresses for material failure with tubular geometry. Thus, the honeycomb model was used to predict compression stresses before material failure, allowing simulation of the behavior of the freeze-cast substrates under homogeneously distributed pressures. This scenario represents more precisely real application conditions, such as for separation processes, providing reliable data to predict the maximum pressures that these substrates can endure.

\section{Experimental}

\subsection{Materials and methods}

The production method of the tubular substrates is already reported elsewhere ${ }^{17,26}$. In summary, ceramic suspensions were prepared with alumina concentrations varying within 10-30 vol\%. These suspensions consisted of commercial alumina powder (Almatis - Alumina CT $3000 \mathrm{SG}$ ), sodium polyacrylate (Sigma-Aldrich) with a concentration of $2 \mathrm{wt} \%$ as a dispersant agent, polyvinyl alcohol $1 \mathrm{wt} \%$ (Sigma-Aldrich) as a binder, and deionized water as solvent. Then, the ceramic suspensions were left stirring for $24 \mathrm{~h}$ and placed in an ultrasound bath for 10 minutes prior to the freezing stage. The suspension was poured in a copper mold $(12.0 \mathrm{~mm}$ and $12.7 \mathrm{~mm}$ of internal and external diameter, respectively, and $58.0 \mathrm{~mm}$ of length) with an internal acrylic cylinder (diameter $8.0 \mathrm{~mm}$ and 58.0 $\mathrm{mm}$ of length) to guarantee tubular shape. The filled copper mold was placed inside liquid nitrogen bath for $30 \mathrm{~s}$ and the frozen alumina substrate was manually withdrawn. The substrates were freeze-dried (Liotop L101 series) for 24 hours. Finally, the dried tubes were heat treated in a conventional furnace (Thermolab - Thermocouple Pt30\%Rh/Pt6\%Rh) at three different temperatures $\left(1300^{\circ} \mathrm{C}, 1400^{\circ} \mathrm{C}\right.$ and $\left.1500^{\circ} \mathrm{C}\right)$.

Experimental data used for the modeling in this study were already reported by Athayde et al. ${ }^{26}$, specifically: porosity by Archimedes' method ${ }^{27}$ and pore diameter by mercury intrusion porosimetry (these results were reproduced in the Appendix, Table A1 and Table A2, respectively). In addition, stereological analyses of the scanning electron microscopy (SEM) micrographs (Figure 1a, b) by the mean linear intercept method ${ }^{28}$ were also used. The mechanical strength of the tubular substrates was determined by an O-ring diametral compression test. These tests were carried out in a universal testing machine (Instron $5882-100 \mathrm{kN}$ ) using samples with $2 \mathrm{~cm}$ in length at a compression rate of $1 \mathrm{~mm} / \mathrm{min}$. For each condition, 5 samples were tested. The stress-strain curve was assessed and the maximum load before complete failure was used as fracture load. The results were compared using two-sample t-test with 0.05 significance level. 


\subsection{Calculation procedures}

The maximum tensile stress $\left(\sigma_{\max }\right)$ in the O-ring diametral compression tests, as reported by Athayde et al. ${ }^{26}$, was assessed by Equation 1:

$\sigma_{\text {max }}=\frac{1,9098 P r_{\text {med }}}{L T^{2}}$

Where $P$ is the maximum load before fracture, $r_{\text {med }}$ is the mean value between the outer $\left(r_{\text {ext }}\right)$ and inner $\left(r_{\text {int }}\right)$ radius, $L$ is the length of the substrate, and $\mathrm{T}$ is the radial thickness $\left(r_{\text {ext }}-r_{\text {int }}\right)$.

The software Microsoft Excel was used for calculation of the stress distribution in the tubular substrates. The equations shown in this study focus on tangential stresses $\left(\sigma_{\theta}\right)$, as previous publication ${ }^{20}$ showed that the axial $\left(\sigma_{\mathrm{a}}\right)$ and radial stresses $\left(\sigma_{\mathrm{r}}\right)$ can be disregarded due to lower values when compared to tangential stresses. For estimation of the tangential stress distribution during the O-ring compression tests, the equations developed by Kranendonk et al. ${ }^{20}$ were implemented in the Microsoft Excel software using VBA (Visual Basic Application) macros (Equations 2-11). This model provided a solution for the stress distribution in the range of $r_{\text {int }} \leq r<r_{\text {ext }}$. It is not possible to find an exact solution in the $r_{\text {ext }}$ due to a lack of convergence of the Fourier expression under boundaries stresses, which tends to infinity under the applied force. Despite this limitation, these equations allow a visualization of the tangential stress concentration in the tubes under such conditions according to the angle and radius.

$$
\sigma_{\theta}=\frac{P}{L \pi r_{e x t}} \times Q(r, \psi)
$$

Where:

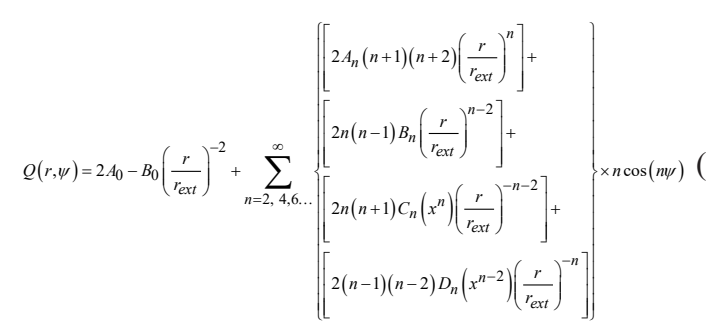

Where:

$$
\begin{aligned}
& A_{0}=\frac{1}{2\left(1-x^{2}\right)} \\
& B_{0}=-\frac{x^{2}}{1-x^{2}} \\
& A_{n}=\frac{1}{2 R_{n}}\left(\frac{1-x^{2 n}}{n}-\frac{1-x^{2 n-2}}{n+1}\right) \\
& B_{n}=\frac{1}{2 R_{n}}\left(\frac{1-x^{2 n}}{n}-\frac{1-x^{2 n+2}}{n-1}\right)
\end{aligned}
$$

$$
\begin{aligned}
& C_{n}=\frac{x^{n}}{2 R_{n}}\left(-\frac{1-x^{2 n}}{n}+\frac{1-x^{2 n-2}}{n+1} x^{2}\right) \\
& D_{n}=\frac{x^{n}}{2 R_{n}}\left(-\frac{1-x^{2 n}}{n} x^{2}+\frac{1-x^{2 n+2}}{n-1}\right)
\end{aligned}
$$

$$
R_{n}=\left(1-x^{2 n}\right)^{2}-n^{2} x^{2 n-2}\left(1-x^{2}\right)^{2}
$$

$$
x=\frac{r_{\text {int }}}{r_{\text {ext }}}
$$

Where $n$ is the index of summation, $r_{e x t}$ is outer radius, $r_{i n t}$ is the inner radius, $L$ is the length of the sample, $P$ is the load applied in the test, $r$ is the radius analyzed, and $\psi$ is the angle between the vertical axis and the analyzed point (Figure 2a).

The strength of a honeycomb structure is described by Equations 12 and 13, representing the fracture stresses of a brittle material when submitted to a load on the $X_{1}$ and $X_{2}$ directions, respectively ${ }^{25}$.

$$
\begin{aligned}
& \left(\sigma_{f r}^{*}\right)_{1}=\sigma_{f s} \times \frac{1}{2\left(\frac{h}{l}+\sin \theta\right)^{3 / 2}} \times \sqrt{\frac{l}{c}} \times\left(\frac{t}{l}\right)^{2} \\
& \left(\sigma_{f r}^{*}\right)_{2}=\sigma_{f s} \times \frac{1}{4 \sqrt{2}(\cos \theta)^{3 / 2}} \times \sqrt{\frac{l}{c}} \times\left(\frac{t}{l}\right)^{2}
\end{aligned}
$$

In these equations, $\left(\sigma_{f r}^{*}\right)_{1}$ and $\left(\sigma_{f r}^{*}\right)_{2}$ are the tensile fracture strengths in direction $\mathrm{X}_{1}$ and $\mathrm{X}_{2}, \sigma_{f s}$ is the rupture modulus (flexural strength) of solid cell wall material when under traction or the compressive strength when under compression (both parameters were assumed constant and the values are $380 \pm 30 \mathrm{MPa}$ and $3000 \pm 500 \mathrm{MPa}$, respectively, for solid cell wall alumina $\left.{ }^{29}\right), h$ is the length of vertical members in honeycombs, $l$ is the length of inclined members in honeycombs, $\theta$ is the angle between the horizontal and inclined members in honeycombs, $c$ is the initial crack length, and $t$ is the thickness of the cell walls. The geometric parameters of the honeycomb cell (Figure 2b) were defined as follows: the angle $\theta$ was maintained in $30^{\circ}$; (a)

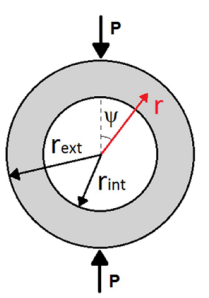

(b)

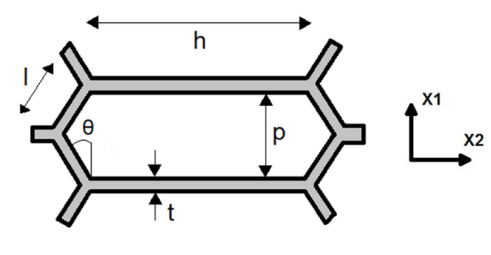

Figure 2. (a) Geometric parameters of the O-ring test used by Kranendonk's equations (2-11) and (b) geometric parameters of a honeycomb cell used by Gibson's equations (12-13). 
the length $l$ was found by trigonometry considering the size $p$ as the value of the average pore diameter assessed by the mercury intrusion porosimetry (Appendix Table A2); the length $h$ was defined as $20 \mu \mathrm{m}$ to represent the lamellar structure of these pores considering the known size $p$; the cell wall thickness $t$ was found by several measures using SEM images (Appendix Table A3); and the initial crack length $c$ was defined as $10 \mu \mathrm{m}$ to be larger than the pore size $p$ of the samples.

The stresses estimated by the honeycomb model were compared with the stress distribution obtained by Equations 2-11 during the O-ring test. The honeycomb model was, then, used to predict the maximum compressive stress that each substrate is able to withstand. These values were used to predict the maximum pressure homogeneously distributed on the surfaces of the substrates. As illustrated in Figure 3b, when the tube is submitted to the application of internal pressure, the tangential stress assumes tensile values, and when external pressure is applied as in Figure 3c, tangential stresses assume compressive values only.

This analysis was performed considering that one of the substrates' surfaces is kept at atmospheric pressure (0.101 MPa), whilst the other surface is submitted to higher fluid pressures. Equation 14 was then used to calculate maximum pressure ${ }^{21}$. Both scenarios (internal and external pressure) were analyzed to compare the behavior of the freeze-cast substrates, as ceramic materials typically show higher mechanical resistance to compressive stresses ${ }^{30}$. This equation allowed estimation of the tangential stress $\left(\sigma_{\theta}\right)$ as a function of the substrate's radius, where $P_{\text {int }}$ is the internal pressure, $P_{\text {ext }}$ is the external pressure, $r_{i n t}$ is the internal radius, $r_{\text {ext }}$ is the external radius, and $r$ is the radius analyzed.

$$
\sigma_{\theta}=\frac{P_{i n t} \times r_{i n t}{ }^{2}-P_{\text {ext }} \times r_{\text {ext }}{ }^{2}}{r_{\text {ext }}{ }^{2}-r_{\text {int }}{ }^{2}}+\frac{r_{\text {int }}{ }^{2} \times r_{\text {ext }}{ }^{2} \times\left(P_{\text {int }}-P_{\text {ext }}\right)}{r^{2} \times\left(r_{\text {ext }}{ }^{2}-r_{\text {int }}{ }^{2}\right)}
$$

\section{Results and Discussion}

\subsection{Substrate properties and maximum tensile stress}

The highly organized pore structure of the tubular freezecast substrates has already been discussed in other reports previously published and is only briefly reproduced in this study for reader's ease ${ }^{17,26}$. The substrates showed radially aligned pores with lamellar geometry (Figure 1a, b), typical of freeze-cast substrates produced from suspensions using water as solvent. The maximum tensile stresses found by Equation 1 for each combination of solid loading and sintering temperature were reproduced in Table 1. This analytical equation assumed that the samples have thin walls (tube radius significantly higher than the tube wall thickness), and the deflection theory for straight beam is applicable ${ }^{18}$. According to Martinez et $\mathrm{al}^{18}$, the consideration of thin walls was appropriate for values of tube wall thickness to tube radius $(h / R)$ within the range of $0.30-0.45$. The $h / R$ ratios found for the alumina freeze-cast tubes were within 0.35 0.37 , thus the consideration was also considered plausible for these samples. The two-sample t-tests revealed that the results were statistically significant, since $87 \%$ of the paired samples (19 out of 22 pairs) showed significant differences.

\subsection{Stress distribution under concentrated pressure (O-ring test)}

From the Equations 2-11, the tangential stress distribution on the freeze-cast substrate when submitted to the O-ring tests was obtained, as shown in Figure 4 for the substrate with $20 \%$ solid loading and sintered at $1500{ }^{\circ} \mathrm{C}$. Material failure took place with highest tensile stresses reaching values as high as 10.6 MPa. These values were located at the inner surface of the tubular substrate and in the plane of the load (angles $0^{\circ}$ and $180^{\circ}$ ). The development of concentrated (a)

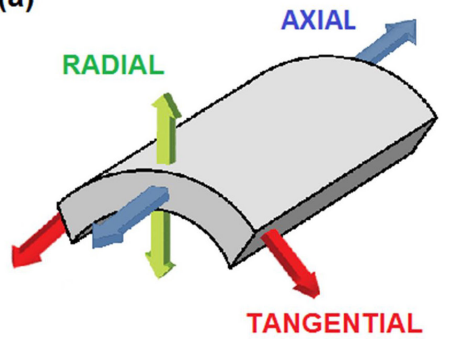

(b)

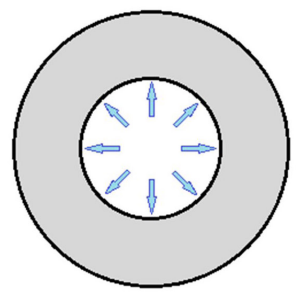

(c)

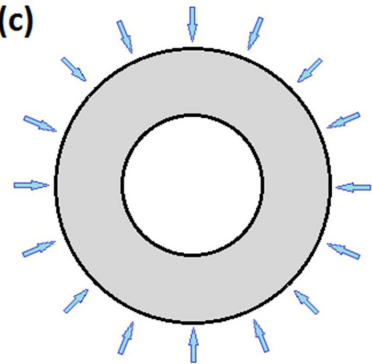

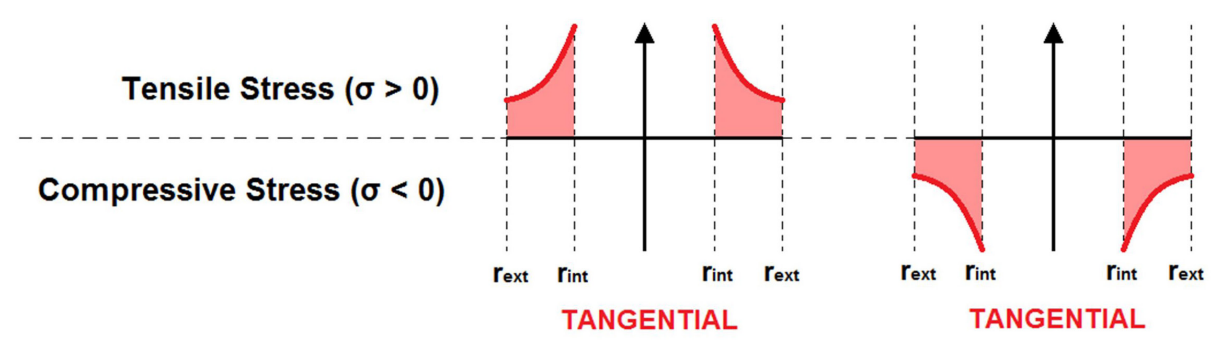

Figure 3. (a) The three types of stresses existing in a tube; and the profile of the tangential stresses along the thickness of a tube under a homogeneous: (b) internal pressure and (c) external pressure, according to Lamé's equation ${ }^{21}$. 


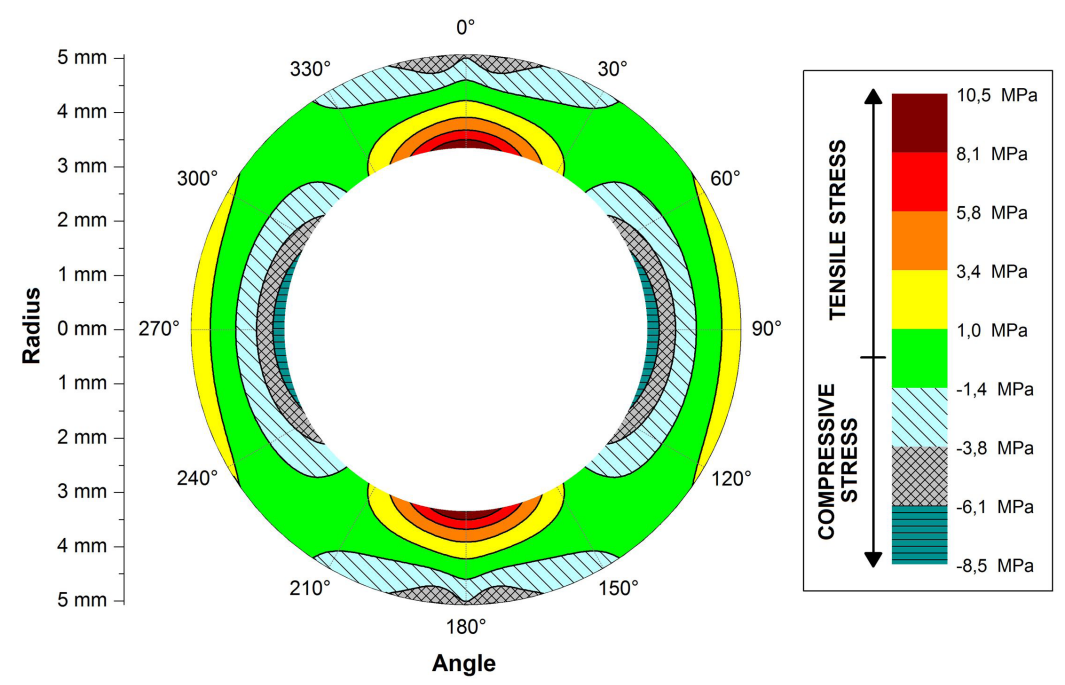

Figure 4. Tangential stress distribution in the tube with $20 \%$ solid loading and sintered at $1500{ }^{\circ} \mathrm{C}$ under maximum loading in the $\mathrm{O}$-ring test.

(a)

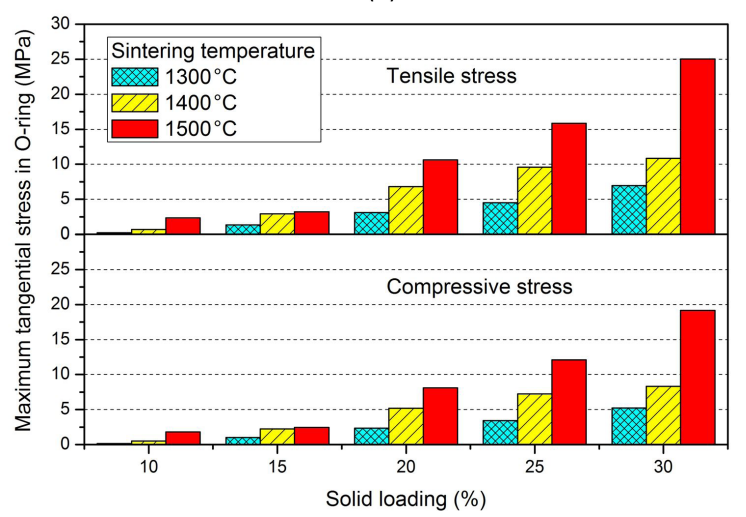

(b)

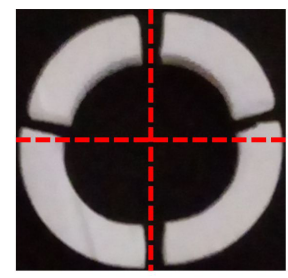

Figure 5. (a) Maximum tangential stress achieved in all samples during the O-ring tests, and (b) observation of the fragments from test sample after failure.

Table 1. Maximum tensile stresses (MPa) assessed in the O-ring diametral compression tests ${ }^{26}$ by the equation developed by Martinez et al. ${ }^{18}$.

\begin{tabular}{cccc}
\hline \multirow{2}{*}{$\begin{array}{c}\text { Solid loading } \\
(\text { vol\% })\end{array}$} & \multicolumn{3}{c}{ Maximum tensile stress $(\mathrm{MPa}){ }^{*}$} \\
\cline { 2 - 4 } & $1300{ }^{\circ} \mathrm{C}$ & $1400^{\circ} \mathrm{C}$ & $1500{ }^{\circ} \mathrm{C}$ \\
\hline 10 & $0.2 \pm 0.1$ & $0.7 \pm 0.1$ & $2.2 \pm 0.7$ \\
\hline 15 & $1.3 \pm 0.3$ & $2.6 \pm 0.1$ & $3.1 \pm 0.8$ \\
\hline 20 & $2.7 \pm 0.2$ & $6.6 \pm 0.5$ & $10.0 \pm 1.4$ \\
\hline 25 & $4.1 \pm 0.2$ & $8.2 \pm 0.7$ & $14.8 \pm 3.1$ \\
\hline 30 & $6.1 \pm 0.8$ & $9.9 \pm 2.1$ & $25.5 \pm 6.8$
\end{tabular}

*Reproduced from published graphs with permission from Athayde et al. ${ }^{26}$, Copyright 2020 WILEY-VCH.

tensile stresses in the tubular geometry was a major factor for the lower mechanical strength of freeze-cast substrates when compared to blocks and cylinders produced by freezecasting, as reported by Athayde et al. ${ }^{26}$.

The tangential stress dropped sharply as the angle $(\psi)$ deviates from the plane of the load. The threshold of compressive stresses began at $\psi$ around $45^{\circ}$, peaking at 8.1 $\mathrm{MPa}$ at the inner surface of the substrate, perpendicular to the plane of load $\left(90^{\circ}\right.$ and $\left.270^{\circ}\right)$. There is also a concentration of compressive stresses at the outer surface, where the substrate is in contact with the equipment. In any other region the stresses were mainly homogeneous and with values significantly lower when compared to the tangential stresses. This is in accordance with previous publications $s^{20}$ and, thus, the radial stresses were not shown in this study.

The maximum stresses for each tubular substrate were estimated using the same procedure and the results are shown in Figure 5. It is clear the tendency of increase in fracture strength for higher solid loading. For instance, the samples sintered at $1400{ }^{\circ} \mathrm{C}$ increased the maximum tensile stress during O-ring test from 0.6 $\mathrm{MPa}$ to $10.8 \mathrm{MPa}$ when the solid concentration increased from $10 \mathrm{vol} \%$ to $30 \mathrm{vol} \%$. This is due to the formation of a more robust structure with smaller pore sizes and higher densities. Moreover, higher sintering temperatures also contributed to the formation of a more consolidated structure with lower intergranular porosity and larger grains. This led to a sharp increase on the maximum tangential stress supported by the material. These findings are in accordance with the results previously 
reported ${ }^{26}$ and estimated by the analytical equation developed by Martinez et al. ${ }^{18}$.

In Figure 5a, the maximum tensile stresses were $\sim 30 \%$ higher than the compressive stresses for all substrates. The load-displacement curves obtained for all substrates showed typical profile of brittle fracture, with one or more cracks taking place during the O-ring compression tests. Due to the higher tensile stresses, as well as the higher brittleness of ceramic materials when under tensile stresses ${ }^{30}$, the failure was initiated by principal cracks at the plane of the load

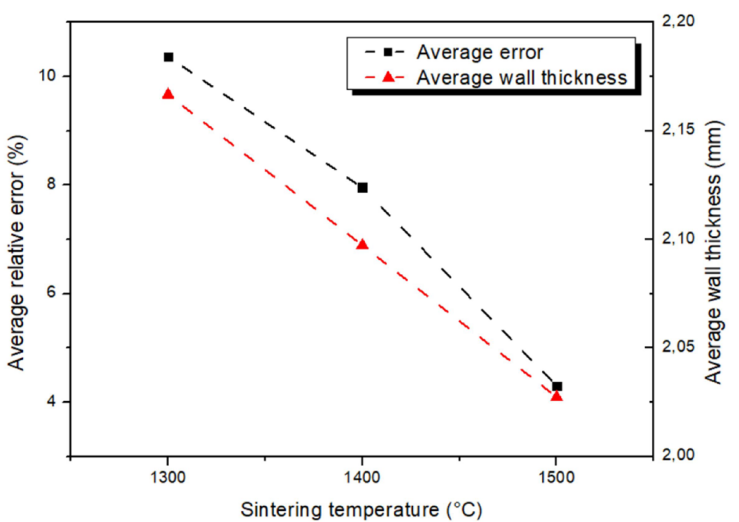

Figure 6. Average relative error, by comparing values in Table 1 and Table 2, and average tube wall thickness plotted against the sintering temperature.

Table 2. Maximum tensile stresses (MPa) found on the spatial stress distribution during O-ring compression tests.

\begin{tabular}{crrr}
\hline \multirow{2}{*}{$\begin{array}{c}\text { Solid loading } \\
\text { (vol\%) }\end{array}$} & \multicolumn{3}{c}{ Maximum tensile stress $(\mathrm{MPa})$} \\
\cline { 2 - 4 } & $1300{ }^{\circ} \mathrm{C}$ & $1400{ }^{\circ} \mathrm{C}$ & $1500{ }^{\circ} \mathrm{C}$ \\
\hline 10 & $0.2 \pm 0.1$ & $0.7 \pm 0.1$ & $2.3 \pm 0.7$ \\
\hline 15 & $1.3 \pm 0.3$ & $2.9 \pm 0.1$ & $3.2 \pm 0.8$ \\
\hline 20 & $3.1 \pm 0.3$ & $6.8 \pm 0.5$ & $10.6 \pm 1.5$ \\
\hline 25 & $4.5 \pm 0.2$ & $9.6 \pm 0.8$ & $15.8 \pm 3.3$ \\
\hline 30 & $6.9 \pm 0.8$ & $10.8 \pm 2.2$ & $25.0 \pm 6.7$ \\
\hline
\end{tabular}

(regions at inner surface in shades of red, around $0^{\circ}$ and $180^{\circ}$ in Figure 4). They were followed by two lateral cracks, resulting in 4 fragments after material failure. As shown in Figure 5b, the lateral cracks (secondary cracks) were found within $60-120^{\circ}$, with respect to the plane of load, as expected by the tensile regions located at outer surface in Figure 4. This failure mechanism is in accordance with a report by Itoh et al. ${ }^{31}$, including an analysis of the crack growth using the finite element method.

The tensile stresses are also detailed in Table 2, for the sake of comparison. In general, the analytical equation developed by Martinez et al. ${ }^{18}$ underestimated the maximum tensile strength during fracture of the tubular freeze-cast substrates. Although the differences between values reported in Table 1 and Table 2 are within experimental error, it was possible to notice that the average relative error decreased for higher temperatures. For instance, the maximum tensile stress in Table 2, calculated by equations developed by Kranendonk et al. ${ }^{20}$, led to values $10,3 \%$ higher for the samples sintered at $1300{ }^{\circ} \mathrm{C}$, whilst for samples sintered at $1500{ }^{\circ} \mathrm{C}$ the average error decreased to $4,3 \%$. This correlation, shown in Figure 6, is attributed to the more intense consolidation of the alumina grains at higher sintering temperatures, contributing to a more dense material with lower average tube wall thickness. Moreover, the samples sintered at $1500^{\circ} \mathrm{C}$ have a more homogenous microstructure, as microstructural defects (such as intergranular pores in the pore wall structure) are found in narrower size distribution for samples sintered at higher temperatures. Thus, the samples sintered at $1500{ }^{\circ} \mathrm{C}$ reached conditions closer to the assumptions of thin walls, as well as the applicability of the straight beam theory, used in Equation 1.

\subsection{Honeycomb model and homogeneously distributed pressure}

The honeycomb model was tested and compared with the tensile stresses obtained from the O-ring compression tests with tubular freeze-cast substrates, as shown in Figure 7. The experimental values showed a high correlation
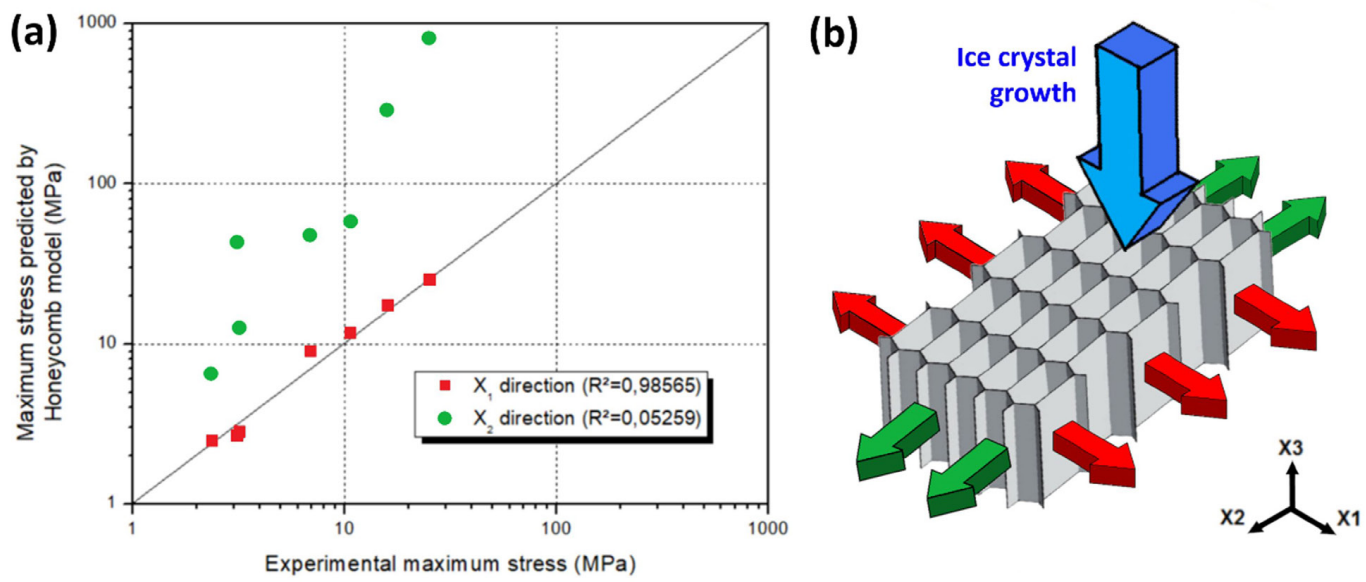

Figure 7. (a) Relationship between the maximum stress supported by the honeycomb structure under traction in the $X_{1}$ and $X_{2}$ directions and the maximum tangential stress achieved in the O-ring test for samples sintered at $1500{ }^{\circ} \mathrm{C}$. (b) Schematic representation of tangential stresses directions acting perpendicular to the pore structure due to the radially aligned ice crystal growth. 
$\left(\mathrm{R}^{2}=0.98565\right)$ with the values assessed by the honeycomb model using the $\mathrm{X}_{1}$ direction, as one may notice by the diagonal line representing equivalent values. As for the $\mathrm{X}_{2}$ direction, the value comparison did not follow a linear trend and the correlation was considerably low $\left(\mathrm{R}^{2}=0.05259\right)$. This outcome suggests that the tangential stress acting in the pore structure is indeed in the $\mathrm{X}_{1}$ direction, as shown in Figure $7 b$. One may notice that the direction of ice crystal growth during suspension freezing establish a radially aligned pore structure that is perpendicular to the tangential stresses when material failure takes place. Therefore, the high correlation on the $\mathrm{X}_{1}$ direction reveals that this model is also adequate to predict the mechanical behavior of tubular substrates produced by freeze-casting.

Based on the high correlation in direction $X_{1}$, the honeycomb model (Equation 12) was also used to estimate the (a)

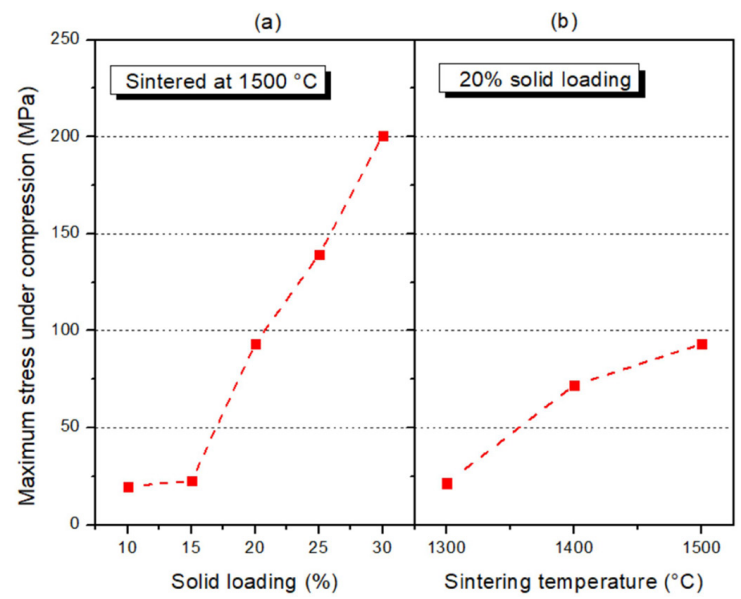

compression stresses that the structure can withstand before fracture (Figure 8). The obtained values were considerably higher than for the tensile stresses, reaching values as high as $200 \mathrm{MPa}$. The solid loading had strong influence on the maximum stresses due to the geometric aspects of the radial pores. For example, as solid loading increases, a more robust cellular structure with lower pore diameter and higher pore wall thickness ( $p$ and $t$, respectively in Figure $2 \mathrm{~b}$ ) were obtained. Geometric parameters of the pores were less influenced by the sintering temperature. Nevertheless, it was still possible to notice correlation between this processing parameter and the maximum stresses, as one may notice in Figure 8b.

Based on the values estimated by the honeycomb model, Equation 14 was used to assess the maximum pressure from a fluid (e.g. liquid) that the freeze-cast substrates can be submitted before failure. This scenario creates a homogeneously distributed pressure throughout the surface of the substrate. In the specific case of pressure applied in the outer surface, which is the most frequent configuration for applications involving fluid transport through porous substrates, the tangential stress profile in the substrate is only composed of compressive stresses. This is clearly shown in Figure 9, where

Table 3. Maximum homogeneously distributed external pressures supported by the tubular substrates sintered at $1500^{\circ} \mathrm{C}$, according to the maximum stresses the structure withstands from the honeycomb model. Atmospheric pressure $(0.101 \mathrm{MPa})$ was applied in the opposite side.

\begin{tabular}{ccc}
\hline \multirow{2}{*}{$\begin{array}{c}\text { Solid loading } \\
(\text { vol\%) }\end{array}$} & \multicolumn{2}{c}{$\begin{array}{c}\text { Maximum uniformly distributed pressure } \\
(\mathrm{MPa})\end{array}$} \\
\cline { 2 - 3 } & External pressure & Internal pressure \\
\hline 10 & 5.9 & 1.2 \\
\hline 15 & 6.8 & 1.4 \\
\hline 20 & 28.4 & 5.3 \\
\hline 25 & 42.2 & 7.8 \\
\hline 30 & 61.5 & 11.4 \\
\hline
\end{tabular}

Figure 8. Maximum compressive stresses predicted by the honeycomb model in the $\mathrm{X}_{1}$ direction that the tubular substrates can withstand before fracture: (a) substrates sintered at $1500^{\circ} \mathrm{C}$, and (b) substrates produced with $20 \%$ solid loading.

$0^{\circ}$
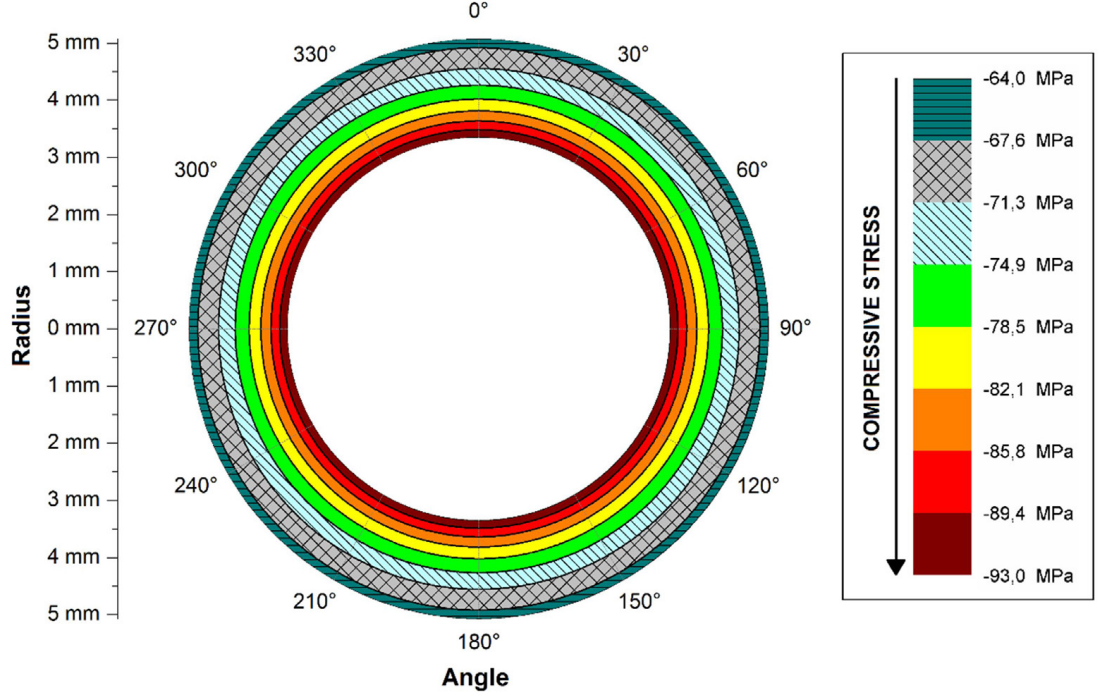

Figure 9. Tangential stress distribution in the tube with $20 \%$ solid loading and sintered at $1500{ }^{\circ} \mathrm{C}$ under maximum uniformly distributed external pressure. 
the maximum compressive stress of 93.3 MPa is reached for the sample produced with $20 \%$ solid loading and sintered at $1500{ }^{\circ} \mathrm{C}$. The compressive stresses were a function of the radius and did not vary with the angle. Highest values of stresses were equally distributed at the inner surface of the substrate. Hence, the crack can propagate in the inner surface when the maximum value of stress is reached for a given flaw size, or where a critical flaw is found. For this sample, the maximum external pressure that could be applied to the outer surface, whilst maintaining the inner surface at atmospheric pressure, was $28.4 \mathrm{MPa}$. Once again, the radial stresses were considerably lower than the tangential stresses and were not shown in this study.

Finally, the maximum uniformly distributed pressures for samples obtained from suspensions with different solid loadings were assessed for all samples sintered at $1500^{\circ} \mathrm{C}$, as shown in Table 3 . The values of the maximum external pressures ranged from 5.9 $\mathrm{MPa}$ to $61.5 \mathrm{MPa}$ when solid loading is increased from $10 \%$ to $30 \%$. The data profile is similar to the one shown in Figure 8a and is reported in Table 3. Meanwhile, for internal pressure, the values ranged within 1.2 and 11.4 MPa. The values revealed that for some of the typical pressure values used in separation processes, such as reverse osmosis that require pressures up to $10 \mathrm{MPa}^{17}$, it's advisable to operate using external pressures with solid loadings higher than $20 \%$ in order to avoid material failure under operation.

The technical difficulties involved in tests with uniformly distributed pressures on tubular geometries make it a hard test to be performed experimentally. The honeycomb model, which was shown to adequately predict the mechanical behavior of the samples developed in this study, can be used to assess the stresses for material fracture of the tubular freezecast substrates under compressive or in tensile scenarios. Furthermore, the estimations from the honeycomb model, allied with Equation 14, allowed the assessment of the substrate's behaviors subjected to homogeneously distributed pressures, a condition that represents more precisely the conditions under regular operation.

\section{Conclusions}

This study showed the use of mathematical models to evaluate the mechanical behavior of tubular freeze-cast substrates with radially aligned pore structure. Based on experimental data from the O-ring tests, the models were tested and compared for different scenarios. The results allowed a spatial stress distribution analysis, revealing that intense tensile stresses were concentrated at the inner surface in the plane of load. These tensile stresses presented maximum values ranging within $0.2-25.0 \mathrm{MPa}$, which initiated material failure by formation of principal cracks. Meanwhile, tensile stresses located in the outer surface at angles within $60-120^{\circ}$ resulted in two secondary lateral cracks, resulting in 4 fragments by the end of the O-ring compression tests. A comparison of maximum tensile stresses obtained by the two methods for mechanical strength assessment showed that the use of a simpler equation is still possible, although there are errors that reached up to $10 \%$, depending on the sintering temperature. High correlation $\left(\mathrm{R}^{2}=0.98565\right)$ between experimental data and the honeycomb model confirmed that this model can precisely predict the failure criterion of tubular freeze-cast substrates. The failure criterion by the honeycomb model was also assessed for the compression scenario, with high correlation to the processing parameters (solid loading and sintering temperature), as expected from previous reports. Finally, modeling of the tubular substrates under homogeneously distributed pressures, which replicates more accurately the real operation conditions for fluid transport, was performed. The tubular freeze-cast substrates were more stable when submitted to external pressures, reaching values up to $61.5 \mathrm{MPa}$, due to the higher strength when under compressive stresses of ceramic materials. Therefore, the assessment of the failure criterion by the honeycomb model allowed modeling of the substrates' mechanical behavior under a condition that is more similar to real operation conditions, though is hard to be experimentally replicated.

\section{Acknowledgments}

The authors gratefully thank the financial support from Brazilian agencies Capes-Proex (433/2010), CNPq (140565/2016-7), Petrobras, and ANP (National Agency of Petroleum, Natural Gas and Biofuel). The authors would like to acknowledge the Center of Microscopy at the Universidade Federal de Minas Gerais (http://www.microscopia.ufmg. br) for providing the equipment and technical support for experiments involving electron microscopy. The authors also thank the Center for the Development of Nuclear Technology (CDTN) for performing the mechanical tests on the tubular substrates and Vale S.A. for the Hg-porosimetry tests.

\section{References}

1. Li Y, Yang X, Liu D, Chen J, Zhang D, Wu Z. Permeability of the porous $\mathrm{Al}_{2} \mathrm{O}_{3}$ ceramic with bimodal pore size distribution. Ceram Int. 2019;45(5):5952-7.

2. Choi HJ, Kim JU, Kim HS, Kim SH, Lee MH. Effect of sintering temperature in preparation of granular ceramic filter. Ceram Int. 2015;41(8):10030-7.

3. Sbrizzai F, Faraldi P, Soldati A. Appraisal of three-dimensional numerical simulation for sub-micron particle deposition in a micro-porous ceramic filter. Chem Eng Sci. 2005;60(23):655163.

4. Jiang H, Meng L, Chen R, Jin W, Xing W, Xu N. Progress on porous ceramic membrane reactors for heterogeneous catalysis over ultrafine and nano-sized catalysts. Chin J Chem Eng. 2013;21(2):205-15.

5. Zhang G, Jin W, Xu N. Design and fabrication of ceramic catalytic membrane reactors for green chemical engineering applications. Engineering. 2018;4(6):848-60.

6. Gao N, Xu ZK. Ceramic membranes with mussel-inspired and nanostructured coatings for water-in-oil emulsions separation. Separ Purif Tech. 2019;212:737-46.

7. Li L, Abadikhah H, Wang JW, Xu X, Agathopoulos S. Onestep synthesis of flower-like $\mathrm{Si}_{2} \mathrm{~N}_{2} \mathrm{O}$ nanowires on the surface of porous $\mathrm{SiO}_{2}$ ceramic membranes for membrane distillation. Mater Lett. 2018;232:74-7.

8. Song X, Jian B, Jin J. Preparation of porous ceramic membrane for gas-solid separation. Ceram Int. 2018;44(16):20361-6.

9. Yoon BH, Choi WY, Kim HE, Kim JH, Koh YH. Aligned porous alumina ceramics with high compressive strengths for bone tissue engineering. Scr Mater. 2008;58(7):537-40.

10. Yoon BH, Koh YH, Park CS, Kim HE. Generation of large pore channels for bone tissue engineering using camphene-based freeze casting. J Am Ceram Soc. 2007;90(6):1744-52. 
11. Julbe A, Farrusseng D, Guizard C. Porous ceramic membranes for catalytic reactors - overview and new ideas. J Membr Sci. 2001;181:3-20.

12. Coronas J, Santamaría J. Catalytic reactors based on porous ceramic membranes. Catal Today. 1999;51:377-89.

13. Deville S, Meille S, Seuba J. A meta-analysis of the mechanical properties of ice-templated ceramics and metals. Sci Technol Adv Mater. 2015;16(4):043501.

14. Liu $\mathrm{R}, \mathrm{Xu} \mathrm{T}$, Wang $\mathrm{C}$. A review of fabrication strategies and applications of porous ceramics prepared by freeze-casting method. Ceram Int. 2016;42:2907-25.

15. Deville S. Freeze-casting of porous ceramics: a review of current achievements and issues. Adv Eng Mater. 2008;10(3):155-69.

16. Araki K, Halloran JW. Porous ceramic bodies with interconnected pore channels by a novel freeze casting technique. J Am Ceram Soc. 2005;88(5):1108-14.

17. Athayde DD, Dolabella ACA, Dias BC, Sousa BM, Silva DG, Vasconcelos DCL, et al. Production and characterization of a silica-alumina membrane using novel tubular freeze-cast substrates. Mater Res. 2019;22(2):e20180639.

18. Martinez AGT, Reboredo MM, Cavalieri AL. Characterization and mechanical behavior of ceramic rings. J Mater Sci. 2007;42(13):5036-45.

19. Jadaan OM, Shelleman DL, Conway JC Jr, Mecholsky JJ Jr, Tressler RE. Prediction of the strength of ceramic tubular components: part I - Analysis. J Test Eval. 1991;19(3):181-91.

20. Kranendonk WGT, Sinnema S. Evaluation of tests for measuring the strength of ceramic tubes. In: Brinkman CR, Duffy SF. STP1201-EB Life prediction methodologies and data for ceramic materials. West Conshohocken, PA: ASTM International; 1994. p. 333-345.
21. Lamé G. Lessons on the mathematical theory of the elasticity of solid bodies. Paris: Gauthier-Villars; 1866. [French].

22. Phalguna BN. Stress and failure analysis of thick walled cylinder with oblique hole. Int J Eng Res Technol. 2017;6(8):36-45.

23. Voorhees HR, Sliepcevich CM, Freeman JW. Thick-walled pressure vessels. Ind Eng Chem. 1956;48(5):872-81.

24. Deville S, Adrien J, Maire E, Scheel M, Di Michiel M. Timelapse, three-dimensional in situ imaging of ice crystal growth in a colloidal silica suspension. Acta Mater. 2013;61:2077-86.

25. Gibson LJ, Ashby MF, Zhang J, Triantafillou TC. Failure surfaces for cellular materials under multiaxial loads - I. modelling. Int J Mech Sci. 1989;31(9):635-63.

26. Athayde DD, Sousa BM, Dolabella ACA, Ribeiro JON, Vasconcelos DCL, Costa JCD, et al. Manufacture of highly porous tubular alumina substrates with anisotropic pore structure by freeze-casting. Adv Eng Mater. 2020;22(7):1901432.

27. ASTM: AMERICAN SOCIETY FOR TESTING AND MATERIALS. ASTM B962-17 - Standard test methods for density of compacted or sintered powder metallurgy (PM) products using Archimedes' principle. West Conshohocken, PA: ASTM International; 2017.

28. ASTM: AMERICAN SOCIETY FOR TESTING AND MATERIALS. ASTM E112-13 - Standard test methods for determining average grain size. West Conshohocken, PA: ASTM International; 2013.

29. Munro RG. Evaluated material properties for a sintered $\alpha$-alumina. J Am Ceram Soc. 1997;80(8):1919-28.

30. Carter CB, Norton MG. Ceramic materials: science and engineering. New York: Springer-Verlag; 2013.

31. Itoh Y, Ikeda M, Suyama S. Fracture behavior of ceramic filter using diametral ring compression test. J Ceram Soc Jpn. 1999;107(12):1196-200. 


\section{Supplementary material}

The following online material is available for this article:

Table A1 - Density of the tubular substrates from porosity measurements ${ }^{26}$ by the Archimedes method.

Table A2 - Average pore diameter ${ }^{26}$ by $\mathrm{Hg}$ intrusion method.

Table A3 - Cell wall thickness assessed from SEM micrographs. 